\title{
Acute hypervolaemia increases gastroduodenal resistance to the flow of liquid in the rat
}

\author{
J Xavier-Neto, A A dos Santos, F H Rola
}

\begin{abstract}
The effect of volume expansion of extracellular fluid on gastroduodenal resistance to the flow of isotonic saline was assessed in three groups of rats using intravenous infusions of isotonic, isotonic-isoncotic, and isotonicisoncotic-isohaemic solutions. The gastroduodenal segment of 29 male Wistar rats was barostatically perfused at a constant pressure gradient of $4 \mathrm{~cm} \mathrm{H} \mathrm{H}_{2} \mathrm{O}$ and changes in flow $(\mathrm{ml} /$ minute) were taken as a reflection of changes in gastroduodenal resistance. Isotonic expansion led to a $33 \%$ drop in gastroduodenal flow compared with the normovolaemic period in the same animals $(\mathbf{p}<\mathbf{0 . 0 1})$. Extracellular fluid expansion with isotonic-isoncotic and isotonic-isoncotic-isohaemic solutions was associated with reductions in gastroduodenal flow of $29 \%(p<0.05)$ and $31 \%(p<0.01)$ respectively. The increase in gastroduodenal resistance is due to hypervolaemia per se and not to haemodilution, decreases in plasma oncotic pressure, or electrolyte imbalance. The effect of hypervolaemia on gastroduodenal resistance, which was reversed by small haemorrhages $(0.5-1.0 \mathrm{ml}$ per $100 \mathrm{~g}$ body weight), may be due to changes in tonus or phasic motor activity, or both, and may be part of the homeostatic processes that help the organism minimise liquid volume excess.
\end{abstract}

In a recent report we showed that acute changes in the extracellular fluid volume were followed by changes in the flow of isotonic saline through the antroduodenal segment of dogs. Acute extracellular fluid volume expansion by intravenous infusion of isotonic saline significantly decreased antroduodenal flow. Conversely, retraction (by haemorrhage) greatly increased it. Since the antroduodenal segment was perfused at a constant pressure during the experiment, the changes in flow were assumed to reflect changes in the resistance(s) of this part of the gastrointestinal tract, possibly changes in tonus or phasic motor activity, or both.'

The gastrointestinal tract seems to react to extracellular fluid volume imbalance by adjusting its intestinal absorption/secretion ratio and its motor function. Acute retraction of the extracellular fluid volume is associated with a significant increase in the intestinal absorption of fluid and electrolytes. ${ }^{23}$ Extracellular fluid volume expansion, on the other hand, is associated with a significant reduction in intestinal absorption or even in secretion of fluid and electrolytes. ${ }^{+}$Acute volume retraction reduces the motor activity of the gastrointestinal tract through the release of catecholamines, ${ }^{5}$ while acute expansion increases jejunal tonus in dogs. ${ }^{6}$ Changes in gastro- intestinal tract motor function may be related to alterations in the absorption/secretion ratio and may contribute to the homeostatic responses that help the organism to compensate for fluid imbalance.'

This view is consistent with reports showing that increased intestinal tonus, per se, is associated with a significant decrease in intestinal absorption of fluid and electrolytes, while decreased tonus is associated with a significant increase in absorption.

Extracellular fluid volume expansion with saline $(\mathrm{NaCl} 0.9 \%)$ infusions lead to haemodilution, reductions in plasma oncotic pressure (favouring interstitial oedema), and electrolyte imbalance $^{8}-$ factors that could possibly influence gastrointestinal motor function. We therefore decided to assess the specificity of the hypervolaemic effect on gastroduodenal resistance by comparing the behaviour of gastroduodenal flow after extracellular fluid volume expansion with isoncotic Ringer solutions as well as with reconstituted homologous blood. A preliminary report of this study has been published. ${ }^{9}$

\section{Materials and methods}

Twenty nine male Wistar rats (190-310 g) were kept for 24 hours without food but with free access to water. The animals were anaesthetised with an intraperitoneal injection of urethane solution ( $1.2 \mathrm{~g}$ per $\mathrm{kg})$ and then underwent tracheostomy. The external jugular or femoral vein and the carotid or femoral artery were cannulated with polyethylene tubing (PE 50). The veins were used for infusion of expanding solutions and drugs, while the arteries were used for bleeding and for blood pressure measurements. Blood pressure (in $\mathrm{mmHg}$ ) was measured continuously. In most experiments an $\mathrm{Hg}$ manometer was used but in group IV we utilised a Statham pressure transducer connected to a polygraph (Narco-Bio-Systems, Houston, Tx, USA). All animals received an intravenous injection of heparin $(500 \mathrm{U}$ in $0.1 \mathrm{ml} \mathrm{NaCl}, 155$ $\mathrm{mM}$ ) to prevent cannula obstruction.

The abdomen was opened by midline incision. The small intestine was exposed and sectioned $3 \mathrm{~cm}$ distal to the pylorus. The distal end was ligated and the proximal one was cannulated so that the tip of the cannula was $2 \mathrm{~cm}$ distal to the pylorus. A gastric probe was introduced by mouth and positioned in the corpus of the stomach. Great care was taken to preserve the regional circulation and innervation.

After surgical preparation was completed, the gastric and duodenal probes were connected to the bottom of their respective barostats (reservoirs of isotonic saline whose liquid levels were kept constant throughout the experiment). 


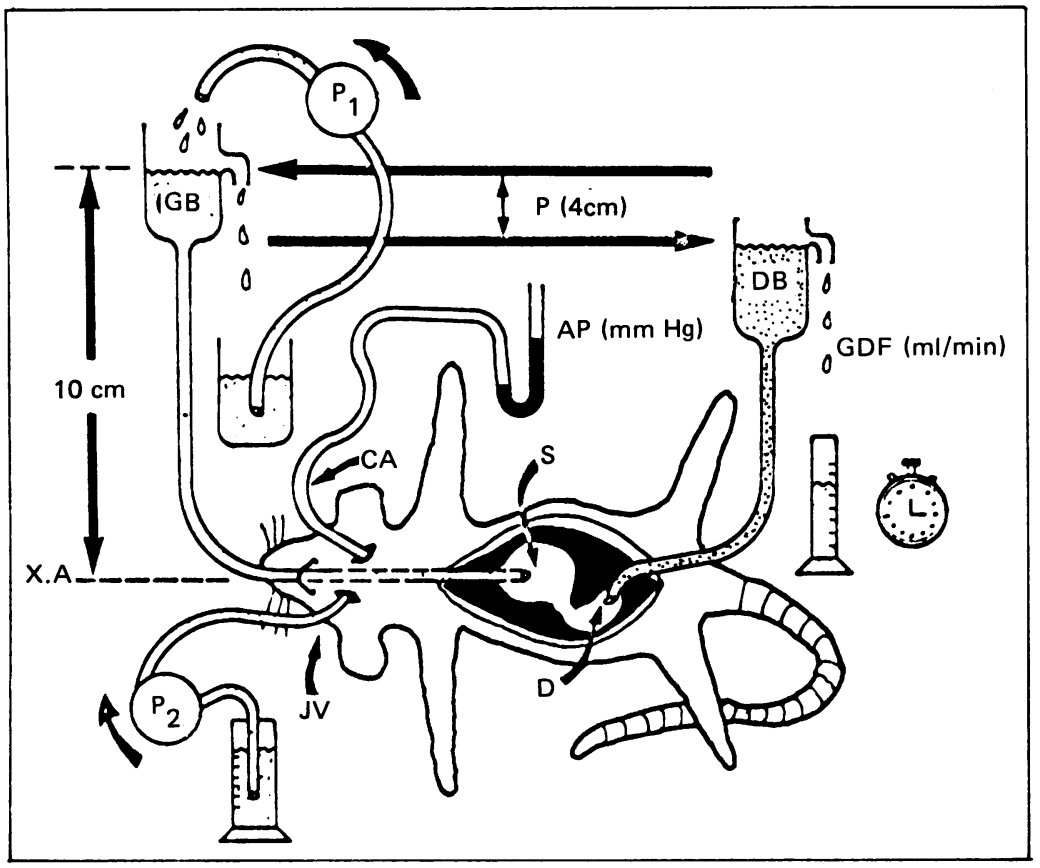

Figure 1: Schematic drawing of the barostat system used to perfuse the gastroduodenal segment of rats with isotonic saline under a constant perfusion pressure.

The gastric barostat $(G B)$ liquid level was always kept $4 \mathrm{~cm}$ above that of the duodenal barostat $(D B)$. The volume of saline flowing out of the $D B$ was collected during two minute intervals and the rate $(\mathrm{ml} / \mathrm{min})$ represented the gastroduodenal flow $(G D F)$.

$P 1$ and $P 2=$ peristaltic pumps; $X A=x y$ phoid appendix; $C A=$ carotid artery; $\mathfrak{F V}=$ jugular vein; $S=$ stomach $; D=$ duodenum; $A P=$ arterial pressure.

The gastric barostat was positioned at different heights in relation to the xyphoid appendix of the rat as required by each experimental protocol, while the liquid level of the duodenal barostat was always kept $4 \mathrm{~cm}$ below that of the gastric barostat. The result was a communicant vessels system with a constant perfusion pressure of $4 \mathrm{~cm} \mathrm{H}_{2} \mathrm{O}$ towards the duodenum in which the resistance to the flow could vary only in the gastroduodenal segment (Fig 1).

The liquid flowing out of the duodenal barostat was collected over two minute intervals and the rate was reported (in ml per minute) as the gastroduodenal flow. In groups I, II, and III the gastroduodenal segment was perfused with isotonic saline at room temperature $\left(28^{\circ} \mathrm{C}\right)$ but in group IV the saline solution was brought to $37^{\circ} \mathrm{C}$ before reaching the gastroduodenal segment by circulating it through a glass coil immersed in a water bath at $38^{\circ} \mathrm{C}$.

\section{EXPERIMENTAL PROCEDURES}

The animals were divided into four experimental groups. Group $1(n=9)$ was used to determine the relation between gastric distension pressure and gastroduodenal flow, as well as to set the gastric barostat level to be used with the other groups. The gastroduodenal segment was perfused at different gastric distension pressures by varying the heights of the gastric barostat relative to the xyphoid appendix $(0,3,5,10$, and $15 \mathrm{~cm})$ but maintaining the resultant perfusion pressure at $4 \mathrm{~cm} \mathrm{H}_{2} \mathrm{O}$. For this, both barostats were simultaneously raised to the required levels. With groups II, III, and IV the gastric barostat height was always $10 \mathrm{~cm}$.

With group II $(n=9)$, we investigated the effect of acute isotonic expansion of the extracellular fluid volume on gastroduodenal flow. Twenty to 30 minutes after stabilisation of blood pressure and gastroduodenal flow (control normovolaemic period) the animals received an intravenous infusion of Ringer's solution $(\mathrm{Na}=$ 140, $\mathrm{K}=4, \mathrm{Cl}=124$, and $\mathrm{HCO}_{3} 20 \mathrm{mmol} / \mathrm{l}$ respectively) at a rate of $1.0 \mathrm{ml}$ per minute up to $10 \%$ of body weight, according to Humphreys and Earley. ${ }^{10}$ The gastroduodenal flow was measured during the 20 to 30 minutes necessary for extracellular fluid volume expansion and then for 20 to 30 minutes afterwards. With group III $(n=6)$ we investigated the effect of isotonic and isoncotic expansion of the extracellular fluid volume on gastroduodenal flow in the same way as in group II, but using Ringer's solution containing bovine serum albumin $6 \mathrm{~g} / \mathrm{l}$. With group IV $(n=5)$ we studied the effect of isotonicisoncotic-isohaemic expansion of the extracellular fluid on the gastroduodenal flow by infusing (in the same way as with groups II and III) red blood cell suspensions in Ringer's solution containing bovine serum albumin $6 \mathrm{~g} / \mathrm{l}$. All expanding solutions were adjusted to a final $\mathrm{pH}$ of $7 \cdot 4$.

In some experiments, dispersed among groups II $(n=4)$, III $(n=1)$, and IV $(n=3)$, the effect of extracellular fluid volume expansion on gastroduodenal flow were not reversed 30 minutes afterwards. In these animals we determined if small haemorrhages $(0.5-1.0 \mathrm{ml}$ of blood $/ 100 \mathrm{~g}$ body weight) would reverse the extracellular fluid volume expansion effect, as has been reported in the dog.'

\section{PREPARATION OF BLOOD CELL SUSPENSIONS AND} ARTERIAL HAEMATOCRIT DETERMINATION

The red blood cells were obtained from four to five donor rats. Blood was collected into heparinised test tubes and then centrifuged at $2500 \mathrm{rpm}$ for 15 minutes. The supernatant plasma was discarded and the red blood cells were washed three times more with Ringeralbumin solution. The red blood cells were resuspended in Ringer-albumin solution to the control haematocrit of each animal to ensure isohaemic expansion. When the surgical preparation had been completed, a $0.5 \mathrm{ml}$ sample of blood was withdrawn from the rat's carotid or femoral artery and centrifuged at $2500 \mathrm{rpm}$ for 15 minutes to estimate the haematocrit. The volume of blood withdrawn was immediately replaced by an equal volume of Ringer-albumin solution.

\section{STATISTICAL ANALYSIS}

Only the gastroduodenal flow values that were three SDs from the mean of the control period were used in analysis. This enabled us to evaluate the latency and duration of the effect of extracellular fluid expansion on gastroduodenal flow. Statistical analyses were carried out for the experimental periods in each group by pooling the data between the intervals defined by the three SD 'cut off' points discussed above, and comparing them with their respective controls using Student's $t$ test for paired means. Inter- 


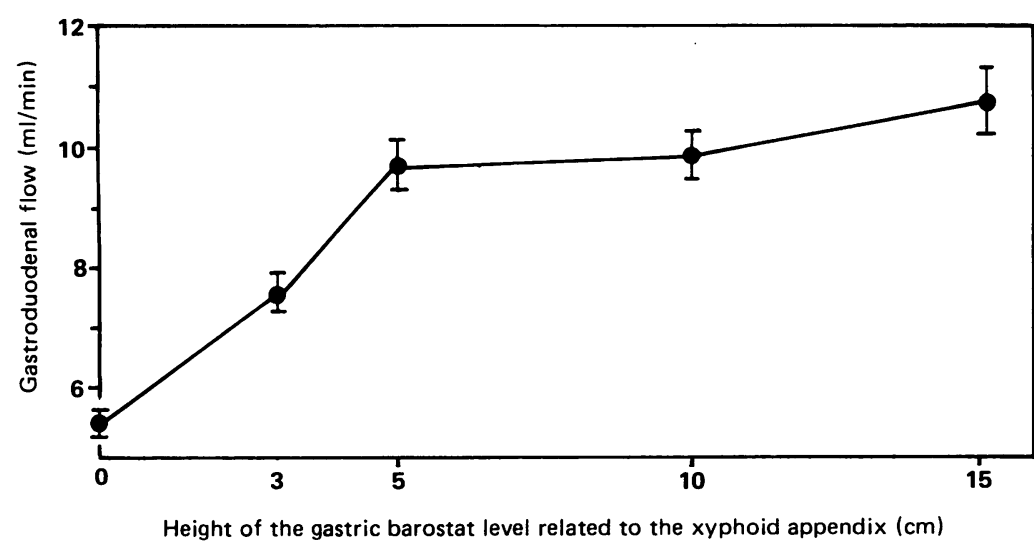

Figure 2: Effects of gastric distension pressure at constant perfusion gradient on the flow of isotonic saline through the gastroduodenal segment of the rat.

Increasing gastric distension pressures were obtained by positioning the gastric barostat 0,3 , 5,10 , and $15 \mathrm{~cm}$ above the xyphoid appendix. A constant pressure gradient was obtained by maintaining the duodenum barostat $4 \mathrm{~cm}$ below the liquid level of the gastric barostat.

group analyses were also made comparing the effect of the three expansion procedures on gastroduodenal flow, latency, and duration of extracellular fluid expansion effect on gastroduodenal flow, and were carried out by Student's $t$ test for unpaired means. The data are expressed as means (SEM).

The gastroduodenal flow latencies in the three groups showed striking variability (see results) and as there were no significant differences between the three expansion procedures we decided to group the animals according to arbitrarily defined criteria for the classification of latencies - that is, slow responders (latencies greater than 10 minutes) and fast responders (latencies between 0 and 10 minutes) - and then represent them in Figure 4 as normalised values of gastroduodenal flow (\% of control mean) at two minute intervals after the start of infusion. Intra- and intergroup statistical analyses were carried out by Student's $t$ test for paired and unpaired means, respectively.

\section{Results}

The data in Figure 2 show that gastroduodenal flow increased linearly with the height of the gastric barostat up to $5 \mathrm{~cm} \mathrm{H}_{2} \mathrm{O}$ above the xyphoid appendix. Gastroduodenal flow did not change appreciably above this height. The gastroduodenal segment behaved as a constant resistance between 0 and $5 \mathrm{~cm}$, while above $5 \mathrm{~cm}$ $\mathrm{H}_{2} \mathrm{O}$ it offered increased resistance to gastroduodenal flow, a feature also observed by others ${ }^{1112}$ and interpreted as evidence for a vagally mediated gastroduodenal reflex. ${ }^{13}$

A gastric barostat height of $10 \mathrm{~cm}$ (which represents the mid-point in the plateau in Fig 2) was used with subsequent groups since it ensured reproducible gastroduodenal flow rates and because a gastric distension pressure of 10 $\mathrm{cm} \mathrm{H}_{2} \mathrm{O}$ does not seem to be far from physiological ranges. ${ }^{1+17}$

Figure 3(a) shows that isotonic expansion of the extracellular fluid volume (group II) led to a $38 \%$ drop in gastroduodenal flow $(\mathrm{p}<0.01)$ compared with the normovolaemic period in the same animals. Figure 3(b) and (c) shows that the extracellular fluid volume expansions that occurred with isotonic-isoncotic (group III) and isotonic-isoncotic-isohaemic solutions (group IV) were associated with reductions in gastroduodenal flow of $31 \%(p<0.05)$ and $39 \%$ $(p<0.01)$ respectively. These results were not statistically different from those observed with plain Ringer solution (group II). Extracellular fluid expansion induced significant blood pressure increases in groups II and IV $(p<0.05)$, but not in group III.

The time course of the gastroduodenal flow reduction caused by acute expansion of the extracellular fluid volume was variable. In 11 experiments the reduction in the gastroduodenal flow began within two minutes of starting intravenous infusion, while in eight it took longer to decrease appreciably (Fig 4) and in one experiment there were no changes in gastroduodenal flow in spite of a $10 \%$ body weight expansion. The variation in the time course was distributed among all groups and so there were no significant differences among groups II, III, and IV in mean latency (8 (7) minutes, group II; 10 (6) minutes, group III; and 10.4 (11) minutes, group IV) or mean duration $(20.7(4 \cdot 8)$ minutes, group II; 20 $(3 \cdot 2)$ minutes, group III; and 16.4 (4.8) minutes, group IV) of the decrease in gastroduodenal flow. The mean thresholds for the expansion effect on the gastroduodenal flow (calculated from the data on latencies and infusion rates) were $3 \cdot 1,3 \cdot 5$, and $4 \cdot 1 \%$ of body weight for groups II, III, and IV respectively.

The Table shows the effect of small haemorrhages on the decrease in gastroduodenal flow induced by extracellular fluid expansion. It can be seen that haemorrhage produced a $58 \%$ reduction in blood pressure values (in relation to the previous condition) $(\mathrm{p}<0.01)$ and brought gastroduodenal flow values close to control levels (NS from control, $\mathrm{p}<0.05$ from the post infusion period).

\section{Discussion}

The present study shows that acute expansion of the extracellular fluid volume is associated with a reduction in the flow of saline through the gastroduodenal segment of the rat. This observation indicates that the extracellular fluid volume somehow modulates the resistance(s) offered to the flow of liquid by the gastroduodenal segment, as previously reported in the dog.'

Expansion of the extracellular fluid volume with solutions containing serum albumin or reconstituted homologous blood induced a reduction in the gastroduodenal flow comparable with that obtained with plain Ringer solution (Fig 3). This indicates that the effect we observed is probably caused by extracellular fluid expansion per se and not by haemodilution, a decrease in the oncotic pressure, or an electrolyte imbalance.

The perfusion system used in this study (Fig 1 ) is an adaptation of that originally described by Miller. ${ }^{12}$ Even though this system was originally developed to reduce the influence of the proximal stomach or the duodenum, or both, on the gastric emptying of liquid meals, we used it to perfuse the gastroduodenal segment under a constant pressure gradient and follow the changes in flow as a reflection of motor activity. 


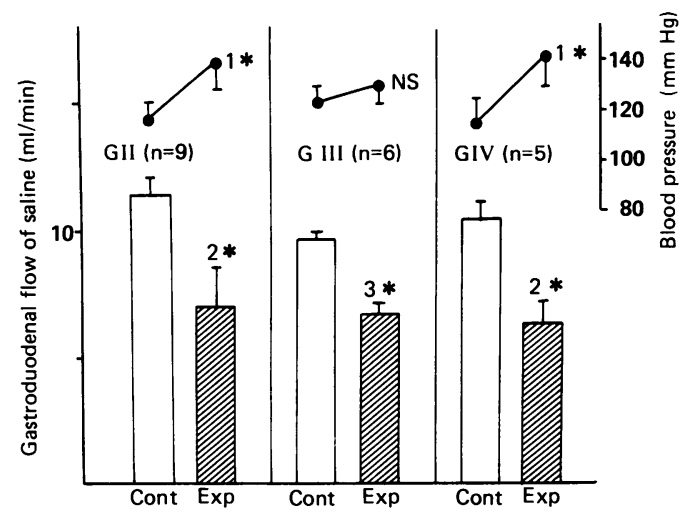

Figure 3: Effects of isotonic, isoncotic, and isohaemic expansions of the extracellular fluid $(E C F)$ volume on gastroduodenal flow (GDF) of saline and of blood pressure $(B P)$ values.

Twenty to 30 minutes after stabilisation of $B P$ and $G D F$ rates (normovolaemic control) animals had their ECF volume expanded by intravenous infusion $(1 \mathrm{ml} / \mathrm{min}$ up to $10 \% \mathrm{bw}$ ) of: Ringer's solution (group II, isotonic); Ringer's solution containing bovine serum albumin $6 \mathrm{~g} / \mathrm{l}$ (Ringer-albumin solution) (group III, isotonic-isoncotic); and isohaemic suspensions of red blood cells in Ringer albumin solution (group IV, isotonic-isoncotic-isohaemic). Acute expansion of the $E C F$ volume induced similar decreases in the $G D F$ in groups II, III, and IV $(33 \% p<0.05 ; 31 \% p<0.01$ and $29 \%$ $p<0.01$, respectively). Increases in $B P$ were statistically significant only in group $I I(p<0.05)$.

Statistical analyses were made for the experimental periods in each group by pooling the data between the intervals defined by a $3 S D$ cut off point (see methods) and comparing them with their respective controls by Student's t test for paired means. Histograms represent absolute $G D F$ rates obtained during normovolaemic control (Cont) and experimental periods $(E x p)$. Vertical bars indicate SEM $I^{\star}=(p<0.05) ; 2^{\star}=$ $(p<0.01) ; 3^{\star}=(p<0.001) ; N S=$ not significant.

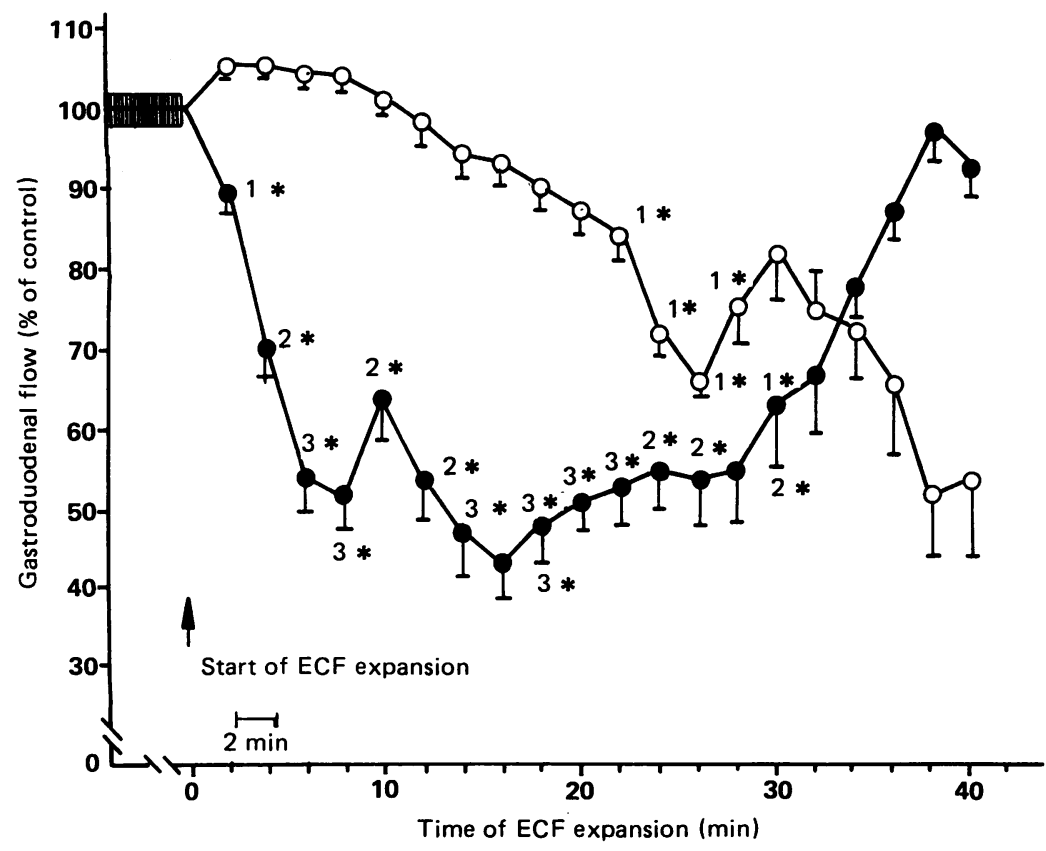

Figure 4: Time course of the extracellular fluid $(E C F)$ volume expansion effect on gastroduodenal flow $(G D F)$ of saline in rats.

Animals from groups II, III, and IV were divided into two groups according to arbitrarily defined criteria for the classification of latency of the ECF expansion effect upon the GDF - that is slow responders for latencies greater than 10 min $(n=7)$ and fast responders for latencies between 0 and 10 min $(n=11)$. The tracings represent normalised values of $G D F(\%$ of control for each experiment) at 2 min intervals taken after the start of ECF expansion.

Intra- and intergroup analyses were carried out by Student's test for paired and unpaired means respectively. Intragroup analysis in the fast responder group showed a significant drop in $G D F 2$ minutes after expansion onset while in the slow responders group a significant decrease in GDF occurred only 22 minutes afterwards. Intergroup analysis showed that both tracings were statistically different from the first 2 minutes until the 24th minute.

The shaded area indicates the variance interval of control values. Open and closed circles represent slow and fast responders respectively. Vertical bars indicate $S E M .1^{\star}=p<0.05 ; 2^{\star}=$ $p<0 \cdot 01 ; 3^{\star}=p<0.001 ; N S=$ not significant.
This approach has been used by others to investigate the behaviour of the various sphincters of the gastrointestinal tract. ${ }^{18} 19$

In a rather complex portion of the gastrointestinal tract such as the gastroduodenal segment, a reduction in gastroduodenal flow might be caused by at least two factors - reduction in the gastroduodenal luminal space due to phasic or tonic contractions and an increase in compliance of the gastroduodenal segment.

In the present experimental model where constant perfusion pressure was applied, increases in gastric or duodenal compliance would induce only transient changes in the gastroduodenal flow instead of the long lasting effect we have observed. This is consistent with observations we have previously made in dogs, where extracellular fluid volume expansion was associated with reduction and not with an increase in gastric ${ }^{20}$ and jejunal compliances. ${ }^{6}$

It is possible that the reductions in gastroduodenal flow described here were caused by phasic or tonic contractions, or both, of the stomach and duodenum. In the dog we observed that acute expansion of the extracellular fluid volume was also accompanied by increased tonus and motility of the duodenum. ${ }^{621}$ This exacerbation of the duodenal contractile activity correlated closely, at least in about $70 \%$ of our experimental observations, with a significant reduction in the gastroduodenal flow. ${ }^{22}$

Even though the results presented in Figure 4 suggest the existence of at least two different groups of animals in relation to the time elapse between the start of extracellular fluid expansion and significant increases in gastroduodenal resistances (slow and fast responders), more work is needed to explain this finding.

We have also observed (Table) that small haemorrhages $(0.5-1.0 \mathrm{ml}$ per $100 \mathrm{~g}$ body weight) counteracted the gastroduodenal flow reduction in rats which had previously been expanded. Catecholamines released during haemorrhage, which reduce the contractile activity of the gastrointestinal tract, ${ }^{5}$ could decrease the resistance offered by the gastroduodenal segment and explain the normalisation of the gastroduodenal flow in rats, or even its increase, as we have observed in the dog.

The increase in gastroduodenal resistance induced by hypervolaemia may be mediated by neural or humoral factors, or both. A nervous reflex could explain the fast onset of gastroduodenal flow reduction in some of our experiments. High blood pressure receptors on the arterial side may be involved, despite the lack of correlation between blood pressure increases and gastroduodenal flow reductions in group III. Even though we have not monitored the central

Effect of small haemorrhages on the reduction in gastroduodenal flow induced by previous expansion of extracellular fluid (ECF) volume with isotonic $(n=4)$, isotonic-isoncotic $(n=1)$, and isotonic-isoncotic-isohaemic $(n=3)$ solutions

\begin{tabular}{llll}
\hline & Control & $\begin{array}{l}\text { ECF volume } \\
\text { expansion }\end{array}$ & $\begin{array}{l}\text { Haemorrhage } \\
(0.5-1.0 \mathrm{ml} / \\
100 \mathrm{~g} \mathrm{bw})\end{array}$ \\
\hline $\begin{array}{c}\text { Gastroduodenal flow } \\
(\mathrm{ml} / \mathrm{min})(\mathrm{n}=8)\end{array}$ & $11 \cdot 1(2 \cdot 2)$ & $\begin{array}{l}6 \cdot 0(3 \cdot 5) \\
\mathrm{p}<0.01\end{array}$ & $\begin{array}{l}10 \cdot 8(3 \cdot 0) \\
(\mathrm{NS})\end{array}$ \\
\hline
\end{tabular}


venous pressure, extracellular fluid volume expansion may reduce gastroduodenal flow by a process affecting the low blood pressure receptors on the thoracic bed.

Humoral factors may play a role in the reduction of gastroduodenal flow induced by extracellular fluid volume expansion. The atrial distension caused by hypervolaemia releases atrial natriuretic factor, ${ }^{23}$ a peptide with potent diuretic and natriuretic properties ${ }^{2+}$ which inhibits the renin-angiotensin-aldosterone axis. ${ }^{25}$ Atrial extracts or atrial natriuretic factor are also able to reduce intestinal absorption of fluid and electrolytes in rats ${ }^{26}$ or in teleost fish. ${ }^{27}$ All these actions could help the organism reduce excess extracellular fluid volume. A recent report shows that atrial natriuretic factor also affects the motor function of the gastrointestinal tract by increasing spontaneous contractions in the rat duodenum. ${ }^{28}$ As this effect is calcium-dependent and is associated with activation of the guanylate ciclase-guanosine monophosphate system, it is possible that increases in intracellular calcium as mediated by atrial natriuretic factor result in enhanced tonus which could ultimately increase gastroduodenal resistance and reduce the rate of intestinal absorption of fluid and electrolytes. ${ }^{79}$

The physiological role of the increase in gastroduodenal resistance(s) due to extracellular fluid volume expansions is not clear. It may, however, be part of the homeostatic processes that help the organism minimise liquid volume excess.

We are indebted to J M Pereira for his technical assistance, Drs M M Sorenson, L J Greene, R B de Oliveira for their helpful comments and to Dr M C Fonteles for the access to some of his laboratory facilities.

1 dos Santos AA, Xavier-Neto J, Pereira JM, et al. Acute changes of the extracellular fluid volume modify the antroduodenal flow of saline in dogs. A possible physiological duodenal flow of saline in dogs. A possib
role. Braz $\mathcal{F}$ Med Biol Res 1988; 21 : 1083-7.

2 Levens NR. Modulation of jejunal ion and water absorption by endogenous angiotensin after hemorrhage. Am fournal Physiol 1984; 246: G634-43.

3 Sjovall H, Abrahamsson H, Westlander G, et al. Intestinal fluid and electrolyte transport in man during reduced circulating blood volume. Gut 1986; 27: 913-8.

4 Duffy PA, Granger DN, Taylor AE. Intestinal secretion induced by volume expansion in the dog. Gastroenterolog 1978; 75: 413-8.

5 Furness GB, Burnstock G. Handbook of Physiology. Sect 7 Endocrinology. Volume IV. Washington: American Physiological Society, 1975: 515-36.

6 Rola FH, dos Santos AA, Xavier-Neto J, et al. Effects of acute volemic changes on jejunal compliance in dogs. Braz $\mathcal{F}$ Med volemic changes on jejunal
Biol Res $1989 ; 22$ : $523-31$.

7 Lee JS. Relationship between intestinal motility, tone, water absorption and lymph flow in the rat. $\mathcal{F}$ Physiol $1983 ; 345$ : 489-99.

8 Nizet A. Comparative role of blood dilution, volume changes and natriuretic factor in sodium excretion. In: Cort $\mathrm{JH}$, Lichardus B, eds. Regulation of body fluids volumes by the kidney. Berlin: S Karger, 1970: 11-6.

9 Xavier-Neto J, dos Santos AA, Rola FH. Acute hypervolemia increases the gastroduodenal resistance to the flow of saline in rats. Procedings of the XXXI International Congress of Physiological Sciences. Helsinki, 1989: 500.

10 Humphreys MH, Earley LE. The mechanism of decreased intestinal sodium and water absorption after acute blood volume expansion in the rat. $\mathcal{F}$ Clin Invest 1971; 50: 2355-67.

11 Gregory RA. Some factors influencing the passage of fluids through intestinal loops in dogs. $\mathcal{F}$ Physiol 1950; 111: 119 37.

12 Miller J, Kauffman G, Elashoff J, Ohashi H, Carter D, Meyer $\mathrm{JH}$. Search for resistances controlling canine gastric empty ing of liquid meals. Am F Physiol 1981; 241: G403-15.

13 Meyer JH. Motility of the stomach and gastroduodenal junction. In: Johnson LR, ed. Physiology of the gastrointestinal tract. 2nd edn. New York: Raven Press, 1987: 613-29.

14 Hakim AA, Lifson N. Effects of pressure on water and solute transport by dog intestinal mucosa in vitro. Am $\mathcal{F}$ Physiol 1983; 216: $276-84$.

15 Lee JS. Effects of stirring on water and glucose absorption by canine mucosal membrane. F Physiol (Lond) 1969; 335: 33541 .

16 Dimaline R, Carter N, Barnes S. Evidence for reflex adrenergic inhibition of acid secretion in the conscious rat. $A m \mathcal{F}$ Pic inhibition of acid secreti

17 Raybould HE, Dockray GJ, Gayton RJ. Cholecistokinin octapeptide (CCK8) can influence the discharge of brainstem neurones from a site in the splanchnic bed [Abstract] Neurosci Lett (suppl) 1985; 22: s115.

18 Edin $R$. The vagal control of pyloric motor function: A physiological and immunohistological study in cat and man. Acta Physiol Scand (suppl) 1980; 485: 1-29.

19 Jarret RJ, Gazet JC. Studies in vivo of the ileocaeco-colic sphincter in the cat and dog. Gut 1966; 7: 271-7.

20 Capelo LR, Cavalcante DM, Leitao IA, Filho GC, da Silva EAT. Modifications of gastric compliance in dogs related to changes of extracellular fluid volume. A possible physiological role. Braz $\mathcal{F}$ Med Biol Res 1983; 16: 73-6.

21 Rola FH, dos Santos AA, Filho GC, Rocha CI, Pereira JM Capelo LR. Modifications of intestinal compliance and motility related to volemic changes in dogs. Braz 7 Med Biol motility related to vol

22 dos Santos AA, Gondim FAA, Santiago Jr AT, Ferreira-Filho AF, Xavier-Neto J, Rola FH. Correlacao entre hipermotilidade duodenal e vazao pilorica (VP) em caes submetidos a expansao aguda do volume do liquido extracelular (VLEC) Ciencia Cultura 1987; 39 (suppl 1): 705

23 Lang RE, Tholken H, Ganten D, Luft FC, Ruskoaho H, Unger TH. Atrial Natriuretic Factor: a circulating hormone stimulated by volume loading. Nature $1985 ; 314: 264-6$.

24 deBold AJ, Borenstein HB, Veress AT, Sonnemberg HA. A rapid and potent natriuretic response to intravenous injection of atrial myocardial extract in rats. Life $S c i 1981$; 28: 89-94.

25 Maack T, Marion DN, Camargo MJF, Kleinert HD, Laragh JH, Vaughan ED, et al. Effects of auriculin (atrial natriuretic factor) on blood pressure, renal function and the renin angiotensin system in dogs. Am F Med 1984; 77: 1069-75.

26 Seeber AM, Vical NA, Carchio SM, Karara AL. Inhibition of water-sodium intestinal absorption by an atrial extract. Can f Physiol Pharm 1986; 64: 244-7

27 O'Grady SM, Field M, Nash MR, Rao MC. Atrial natriuretic factor inhibits Na-K-Cl cotransport in teleost intestine. $A m$ f Physiol 1985; 249: C531-4.

28 Bayeens DA, Walters JM, Versely DL. Atrial natriuretic factor increases the magnitude of duodenal spontaneous phasic contractions. Biochem Biophys Res Commun 1988; 155: 1437-43.

29 Berridge MJ. A general survey of the mechanism and control of intestinal fluid transport. Scand $\mathcal{F}$ Gastroenterol 1983; 587 . of intestir 